\title{
How do new mothers perceive screening for perinatal depression?
}

\begin{abstract}
BACKGROUND
Countries recognize the risk of mental health difficulties during the perinatal period and the potential benefits of screening and early detection of depressive symptomatology. This study aimed to analyse mothers' views on screening for postpartum depression (PPD) in Poland, where a new standard of perinatal care imposed (from January 2019) the obligation to monitor women' postpartum mental state.
\end{abstract}

\section{PARTICIPANTS AND PROCEDURE}

150 women participated in the study. In the first stage, PPD symptoms were assessed with the Edinburgh Postnatal Depression Scale (EPDS) among postpartum women during midwives' home visits. The second stage consisted of a telephone survey with the EPDS and questions exploring mothers' perception of midwife competencies in screening for PPD.

\section{RESULTS}

Most women identified as relatively high midwives' competencies in communicating information about PPD, in- terpretation of the EPDS score and their ability to create comfortable conditions of the assessment and further discussion about postpartum mental health changes. Women with an elevated level of PPD symptoms assessed as significantly lower midwives' competence in this last aspect and those who had a caesarean section tend to assess as lower the usefulness of provided information on care of a newborn.

\section{CONCLUSIONS}

Midwives should be aware and prepared for a possible critical attitude of patients, which may be a sign of a depression. Otherwise, medical staff may not be willing to interact with a mother and offer her help and support. The ability to create a friendly condition in spite of adversity can contribute to the desire of women to undergo screening, discussion about the result and further treatment.

\section{KEY WORDS}

mental health; postpartum depression; Edinburgh Postnatal Depression Scale; screening; perinatal care

ORGANizAtion - 1: Institute of Psychology, University of Gdansk, Gdansk, Poland · 2: Department of Psychology, Gdansk University of Physical Education and Sport, Gdansk, Poland

Authors' Contributions - A: Study design - B: Data collection - C: Statistical analysis - D: Data interpretation .

E: Manuscript preparation · F: Literature search · G: Funds collection

CORRESPONDING AUthor - Tamara Z. Walczak-Kozłowska, Ph.D., Department of Psychology, Gdansk University of Physical

Education and Sport, 1 Górskiego Str., 80-336 Gdansk, Poland, e-mail: tamara.walczak-kozlowska@awf.gda.pl

TO Cite this ARTICLE - Chrzan-Dętkoś, M., \& Walczak-Kozłowska, T. Z. (2021). How do new mothers perceive screening

for perinatal depression? Health Psychology Report, 9(3), 207-216. https://doi.org/10.5114/hpr.2021.102823

RECEIVED 27.08.2020 • REVIEWED 26.11.2020 • ACCEPTED 15.12.2020 • PUBLISHED 18.01.2021 


\section{BACKGROUND}

Perinatal mood disorders are a common and serious mental health problem: postpartum depression (PPD) affects about $13-20 \%$ of new mothers and antenatal depression occurs in as many as $19 \%$ of all pregnant women (O’Hara \& McCabe, 2013; Rubertsson et al., 2005). Mental disorders in the perinatal period can severely harm women and their children if not detected early and treated appropriately (Netsi et al., 2018). Antenatal depression increases the risk of premature labour (Orr \& Miller, 1995; Dayan et al., 2006; Goldenberg et al., 2008), preeclampsia (Grote et al., 2010; Wallis \& Saftlas, 2009), diabetes in pregnancy (Kurki et al., 2000), epidural anaesthesia and caesarean section (Kozhimannil et al., 2009; Andersson et al., 2004; Wu et al., 2002). Moreover, psychiatric disorders are still one of the leading indirect causes of maternal morbidity and death in the postpartum period (Knight et al., 2017; Wisner et al., 2019). Suicide, which may be the result of untreated depression, accounts for $20 \%$ of deaths among postpartum women and is the second leading cause of mortality in the first year postpartum (Kendig et al., 2017).

Additionally, given that the mother's depression (both during pregnancy and after delivery) is related to the child's cognitive and emotional functioning even at the age of 18 (Netsi et al., 2018), early detection of depressive symptoms in the perinatal period seems particularly important for the further relationship in a mother-child dyad and child development. The American Academy of Paediatrics released, as the first national paediatric association, an important statement recognizing that "maternal depression affects the whole family" and urged paediatric providers to "incorporate recognition and management of perinatal depression into paediatric practice" (Earls et al., 2019, pp. 1-2). The existing practice of midwives' postpartum home visits and control visits at the paediatricians' office creates a favourable circumstance for the provision of early postpartum mental health screening. Worldwide, midwives and nurses have frequent contact with pregnant and postpartum women: at least once a month in the prenatal period and a few times in the postpartum period (in Poland); hence, they are well positioned to provide depression screening and counselling. In many countries such as Australia and the UK nurses and midwives are obliged to screen for depressive and/or anxiety symptomatology in the perinatal period. Additionally, some countries (for instance the US), recognizing that the period of the first few weeks postpartum is not sufficient for screening, extended this period to the first 12 months of a child's life.

Increasingly the burden of early detection and treatment of postpartum depression rests on nurses and midwives, and it seems to be not always easy. The study of Mollart et al. (2009) revealed that midwives felt frustrated at the lack of referral pathways when women disclosed the need for help. Also, in Jones et al.'s study (2012a, 2012b) on Australian midwives' awareness and management of antenatal and postnatal depression, the midwives lacked competency in identifying depression and its appropriate subsequent management. Our earlier study (Chrzan-Dętkoś \& Walczak-Kozłowska, 2020) revealed that Polish midwives are not properly prepared for the assessment of a woman's mental state even though they are obliged to screen for PPD and its risk factors (this was imposed by the introduction of a new national standard of perinatal care on January 1, 2019). Their knowledge and competencies of pre- and postnatal depression turned out to be relatively low, as compared to their knowledge and competencies in other professional tasks. Most of the assessed midwives admitted that they were not adequately educationally prepared for screening and providing care and support for women with antenatal depression and/or PPD. Carrying out screening for postpartum depression causes confusion in the community of nurses and midwives as the Ministry of Health has not identified specific tools to assess the risk of depression and the severity of its symptoms. Moreover, there is a lack of guidance and appropriate training for medical personnel regarding the interpretation of the results of commonly available screening methods (e.g. the Edinburgh Postnatal Depression Scale, EPDS). There are also no guidelines for referring women with severe symptoms of postpartum depression so that they can receive quick help from the National Health Fund.

However, while we have some knowledge about midwives' perception of screening, less is known about how new mothers perceive such an assessment and questions concerning their mental health. What we know from the few existing studies is that women with perinatal mental health problems often do not seek help (Fonesca et al., 2015). Bayrampour et al.'s study (2017) revealed that a number of women reported not communicating their emotional struggles because they were uncertain whether these concerns were normal. The fear of stigmatization as a 'bad mother' seems a major factor impeding asking for help and revealing the emotional burden. Additionally, what seems to be particularly alarming, women who could benefit most from early help frequently are those who are hesitant towards screening: a previous diagnosis of a mental health issue in a history was more common among women who identified harms associated with screening than among those who did not (38\% vs. 22\%) (Kingston et al., 2015a). In a Canadian study a potential harm associated with screening was reported by $17 \%$ of respondents. The most common harms listed by the new mothers were: feeling embarrassed, feeling worried about what would happen with the information, not knowing why certain questions were asked, finding the experi- 
ence to be negative, and finding the questions or the way questions were asked uncomfortable (Kingston et al., 2015a, b). Another important factor concerning screening is honesty: during mental health screening in pregnancy one in five pregnant women reports being somewhat honest or not honest at all (Kingston et al., 2015c). Some further conclusions concerning perinatal mental health screening can be based from the studies on patients suffering from depression. People with mental health illness experience difficulties with being diagnosed as having depression (Dinos et al., 2004). According to Cornford et al. (2007), there is a remarkable difference between the medical and the patients' view of the concept of depression. According to many people, depression is not the right label for their problems and a negative view of depression is related to a fear of stigmatization.

As in Poland the screening was implemented in January 2019 and is still a novelty, we aimed to find out how Polish women feel about screening and talking about mental health concerns with midwives. In North America, mothers who sought help reported feelings of humiliation, frustration, and anger, all resulting from their interaction with healthcare professionals (Logsdon et al., 2012). Meanwhile, Australian women reported that their physicians had behaved patronizingly and had preferred to prescribe medications that relieved the symptoms of PPD rather than offer counselling (Jones et al., 2011).

On the basis of the new national standard of perinatal care (Dziennik Ustaw, 2018), the Polish Ministry of Health implemented regional programmes aimed at screening postpartum mental health disorders and offering quick support in the place of a woman's residence. Regional programmes are financed from the public funds and are co-financed by the European social funds. One of them is the project 'Next Stop: MUM' (no. POWR.05.01.00-00-0023/18), which was implemented in the northern macro-region of Poland by the Copernicus Healing Entity along with the Institute of Psychology at the University of Gdansk in mid2019. Midwives taking part in the project are equipped with proper assessment tools (the Edinburgh Postnatal Depression Scale), have the opportunity to benefit from psychological supervision in order to discuss and cope with difficult situations they face during screening, and participate in training concerning perinatal mental health. In the case of an elevated result obtained by a patient on the EPDS scale, midwives can refer a woman for psychological consultations.

As the project's implementers in the northern macro-region of Poland, we aimed to find out how new mothers evaluate screening procedures conducted by midwives. We were particularly interested in the assessment of midwives' communication competencies (communicating information about PPD and interpretation of the EPDS score), their ability to create comfortable conditions of the assessment and further discussion about postpartum mental health changes, as well as the usefulness of provided information on care of a newborn. We also wanted to find out whether the assessment of the above competencies may vary depending on the type of delivery - natural birth vs. caesarean section (CS). It is important in our country as Poland has one of the highest CS rates in Europe: in 2017 43.9\% of all women who gave birth delivered by CS (Polityka Zdrowotna, 2019). A recent meta-analysis carried out by $\mathrm{Xu}$ et al. (2017) suggests that CS, as well as emergency $\mathrm{CS}$, increases the risk of postpartum depression. Additionally, as Swain et al.'s study (2008) showed, there are some significant differences in brain response to infant crying even 2 to 4 weeks after birth in the group of vaginal delivery (VD) and CS delivery (CSD) mothers. CSD mothers in comparison with VD mothers were found to be less sensitive to their infant crying. On this basis we hypothesized that mothers after CS may differ in their assessment of midwives' competencies and may require more support as well as broader information about the childcare.

\section{PARTICIPANTS AND PROCEDURE}

\section{PARTICIPANTS}

One hundred and fifty women participated in the study. The average age of the respondents was 29.99 years $(S D=4.61, \min =19$, $\max =41)$. Ninetyeight percent of women gave birth to a one child, and the remaining $2.0 \%$ gave birth to twins. On average, women had overall (including newborn and older children) 1.83 children $(S D=0.87, \min =1$, $\max =6)$. Almost three-quarters $(72.7 \%)$ of women were married, $23.3 \%$ were in an informal relationship, whereas $4.0 \%$ were single parents. Nearly half of participants ( $55.7 \%$ women) had higher education, $31.5 \%$ had secondary education, $9.4 \%$ basic vocational education and $3.4 \%$ had junior high school education. Most of the participants (62.5\%) lived in big cities (over 250,000 residents), $22.9 \%$ were residents of villages, $6.3 \%$ lived in cities with up to 50,000 residents, $4.9 \%$ lived in cities with up to 250,000 residents and $3.5 \%$ lived in cities with up to 100,000 residents. Most women $(58.0 \%)$ stated that they had a good standard of living, $27.3 \%$ very good, $12.7 \%$ average, $1.3 \%$ bad and $0.7 \%$ stated that they had a very bad standard of living.

\section{PROCEDURE}

The study consisted of two stages. In the first stage, postpartum consultations in the project 'Next Stop: MUM' were conducted by midwives during home visits within two weeks after childbirth. During such
Mother's perception of screening for perinatal depression 
a visit, the midwife conducted a standard health examination of a woman and her baby. The midwife also provided information on newborn care and postpartum mental health changes (with the discussion about PPD risk) as well as conducting a screening test for PPD symptoms with the EPDS scale, and, in the event of an elevated result, talked about mental health promotion and motivated the new mother to seek further help. Midwives conducting consultations received remuneration from the project's implementers.

The second stage of the study was conducted via telephone interviews conducted by master's degree students from the University of Gdansk (Faculty of Psychology). During the interview women responded to EPDS statements and questions about medical and demographic issues as well as being asked to assess midwives' competences in conducting consultations in the project 'Next Stop: MUM' in terms of: (1) usefulness of information on newborn care, (2) communication competences in providing information on PPD and interpretation of the result obtained by a woman on the EPDS scale, (3) ability to create comfortable conditions of the assessment and discussion about postpartum mental health changes.

The protocol of this study was approved by the Ethics Board for Research Projects at the Institute of Psychology, University of Gdansk, Poland (decision no. 20/2019).

\section{MEASURES}

Edinburgh Postnatal Depression Scale. The Edinburgh Postnatal Depression Scale (EPDS; Cox et al., 1987) is a 10-item questionnaire, providing self-reported information about existence and severity of depressive symptoms in the postpartum period. A score ranging from 10 to 12 is considered to indicate possible depression with the recommendation of further assessment. This tool is recommended by the American Medical Association (see Felder, 2019) as a screening method when used by medical personnel who do not directly provide psychological/psychiatric services.

Telephone survey about midwives' competencies. The survey consists of questions about medical and demographic issues as well as three additional statements in which women were asked to assess midwives' competencies. In the first statement, the woman assessed the usefulness of the information provided by the midwife on newborn care - on 7-point Likert scale from 1 (useless) to 7 (very useful). The second formulation concerned the midwife's communication competence - her ability to clearly communicate knowledge about postpartum depression and interpretation of the EPDS score obtained by a woman (7-point Likert scale, where 1 meant low and 7 meant high). The third statement concerned the assessment of the midwife's ability to create comfortable conditions when assess- ing the severity of depressive symptoms via the EPDS and during a conversation about the postpartum mental health changes (7-point Likert scale, where 1 meant a feeling of awkwardness and 7 meant a feeling of very good comfort).

\section{RESULTS}

For the purpose of statistical analyses, we used IBM SPSS Statistics, version 24.0. After excluding the missing answers, further analyses included 147 observations. Before performing the analyses, data were tested for normality using the Kolmogorov-Smirnov test, which revealed that the results obtained by women in the EPDS assessments and the results of their evaluations of midwives' competencies differ significantly from the normal distribution. Therefore, analyses were performed using nonparametric coefficients (Friedman and Spearman's rho) and were preceded by the statistical description of the variables.

The average result obtained by women in the first EPDS assessment was $3.90(S D=3.67, \min =0$, $\max =25)$. In turn, during telephone surveys, two months later, the average result obtained by the same group of women was $4.41(S D=3.67, \min =0$, $\max =25)$. However, the difference between those two measurements was statistically insignificant $\left(\chi^{2}=.01, p=.928\right)$.

During telephone conversations with the interviewer, women evaluated midwives' competencies in conducting postpartum consultations in the three aspects (see Table 1). Usefulness of information on newborn care provided by a midwife was rated the highest. Midwife's competence in communicating information about PPD and interpretation of the EPDS score was rated the lowest.

A significant correlation was found between the severity of PPD (results obtained in both assessments with the EPDS scale) and women's assessment of midwives' competences in the aspect of the ability to create comfortable conditions of the assessment and further discussion about postpartum mental health changes during consultation (see Table 2 for details). A significant correlation was also revealed between the severity of PPD symptoms two months after midwives' consultations (during telephone interviews) and the assessment of midwives' competencies in communicating information about PPD and interpretation of the EPDS score.

Symptoms of PPD for most of the examined women were within the normal (non-clinical) range; only 9 women obtained an elevated EPDS score (10 points and above) during the first assessment (during the midwife's home visit) and 18 women during a telephone conversation two months later. Further MannWhitney analysis revealed that women who had elevated EPDS scores evaluated as significantly lower 


\section{Table 1}

Assessment of individual aspects of midwives' competencies in conducting postpartum consultations in the project 'Next Stop: MUM'; evaluations were given retrospectively by patients via telephone interview $(N=147)$

\begin{tabular}{|c|c|c|c|c|c|}
\hline $\begin{array}{l}\text { Aspects of the assessment of midwife's competence in } \\
\text { conducting consultation }\end{array}$ & $M$ & $S D$ & Min & Max & \\
\hline $\begin{array}{l}\text { Usefulness of information on newborn care provided by } \\
\text { midwife }^{1}\end{array}$ & 6.69 & 0.78 & 2.00 & 7.00 & \\
\hline $\begin{array}{l}\text { Midwife's competence in communicating information } \\
\text { about PPD and interpretation of the EPDS score }\end{array}$ & 6.55 & 1.12 & 1.00 & 7.00 & $\begin{array}{l}\text { Mother's } \\
\text { perception }\end{array}$ \\
\hline $\begin{array}{l}\text { Midwife's ability to create comfortable conditions of the } \\
\text { assessment and further discussion about postpartum } \\
\text { mental health changes }{ }^{3}\end{array}$ & 6.59 & 1.23 & 1.00 & 7.00 & $\begin{array}{l}\text { of screening } \\
\text { for perinatal } \\
\text { depression }\end{array}$ \\
\hline
\end{tabular}

Note. ${ }^{1}$ 7-point Likert scale from 1 (useless) to 7 (very useful); ${ }^{2}$ 7-point Likert scale from 1 (low) to 7 (high); ${ }^{3}$ 7-point Likert scale from 1 (a feeling of awkwardness) to 7 (a feeling of very good comfort).

\section{Table 2}

Relationships (Spearman rho coefficient) between the EPDS scores obtained by women and their evaluations of midwives' competencies in the project 'Next Stop: MUM' $(N=147)$

\begin{tabular}{|c|c|c|}
\hline \multirow{2}{*}{$\begin{array}{l}\text { Aspects of the assessment of midwife's competence } \\
\text { in conducting consultation }\end{array}$} & \multicolumn{2}{|c|}{ EPDS score obtained by women } \\
\hline & $\begin{array}{l}\text { during direct } \\
\text { consultations } \\
\text { with midwives }\end{array}$ & $\begin{array}{l}\text { during telephone } \\
\text { interviews two } \\
\text { months later }\end{array}$ \\
\hline $\begin{array}{l}\text { Usefulness of information on newborn care provided } \\
\text { by midwife }{ }^{1}\end{array}$ & -.02 & -.07 \\
\hline $\begin{array}{l}\text { Midwife's competence in communicating information } \\
\text { about PPD and interpretation of the EPDS score }\end{array}$ & -.13 & $-.20^{*}$ \\
\hline $\begin{array}{l}\text { Midwife's ability to create comfortable conditions of the } \\
\text { assessment and further discussion about postpartum mental } \\
\text { health changes }{ }^{3}\end{array}$ & $-.19^{*}$ & $-.30^{* *}$ \\
\hline
\end{tabular}

midwives' ability to create comfortable conditions of the assessment and further discussion about postpartum mental health changes (see Table 3 for details).

Among interviewed women, $61.2 \%$ had a natural birth, $26.5 \%$ had a caesarean section, whereas $12 \%$ did not provide information in this matter. There were no significant differences between the groups (natural birth vs. CS) in the EPDS scores both in the first $(U=1665.50, p=.514)$ and the second measurement $(U=1500.00, p=.137)$. Further analysis aimed to verify the differences between women after natural childbirth $(n=90)$ and CS $(n=39)$ in the evaluation of postpartum consultations held by midwives. The group of women after CS assessed the usefulness of information on newborn care provided by midwives lower (at the level of a trend) in comparison to those women who had a natural childbirth (see Table 4 for details).

\section{DISCUSSION}

This study investigated women's perception of midwives' competences in conducting postpartum screening for PPD. To our knowledge, it is the first research to assess the perception of mental health screening after the implementation of a new standard of perinatal health in Poland in 2019.

The majority of women from our study identified midwives' competencies in communicating information about PPD and interpretation of the EPDS scores as well as their ability to create comfortable conditions of the assessments and further discussion about postpartum mental health changes at a relatively high level. The highest scores were given to the midwives' competence in providing useful information on newborn care. Moreover, we observed a significant 


\section{Table 3}

Differences in evaluations of midwives' competencies in conducting postpartum consultation between women with normal (non-clinical; in the first assessment: $n=138$; in the second assessment: $n=129$ ) and elevated (clinical; in the first assessment: $n=9$; in the second assessment: $n=18$ ) intensification of postpartum depression symptoms (10 or more points on EPDS scale)

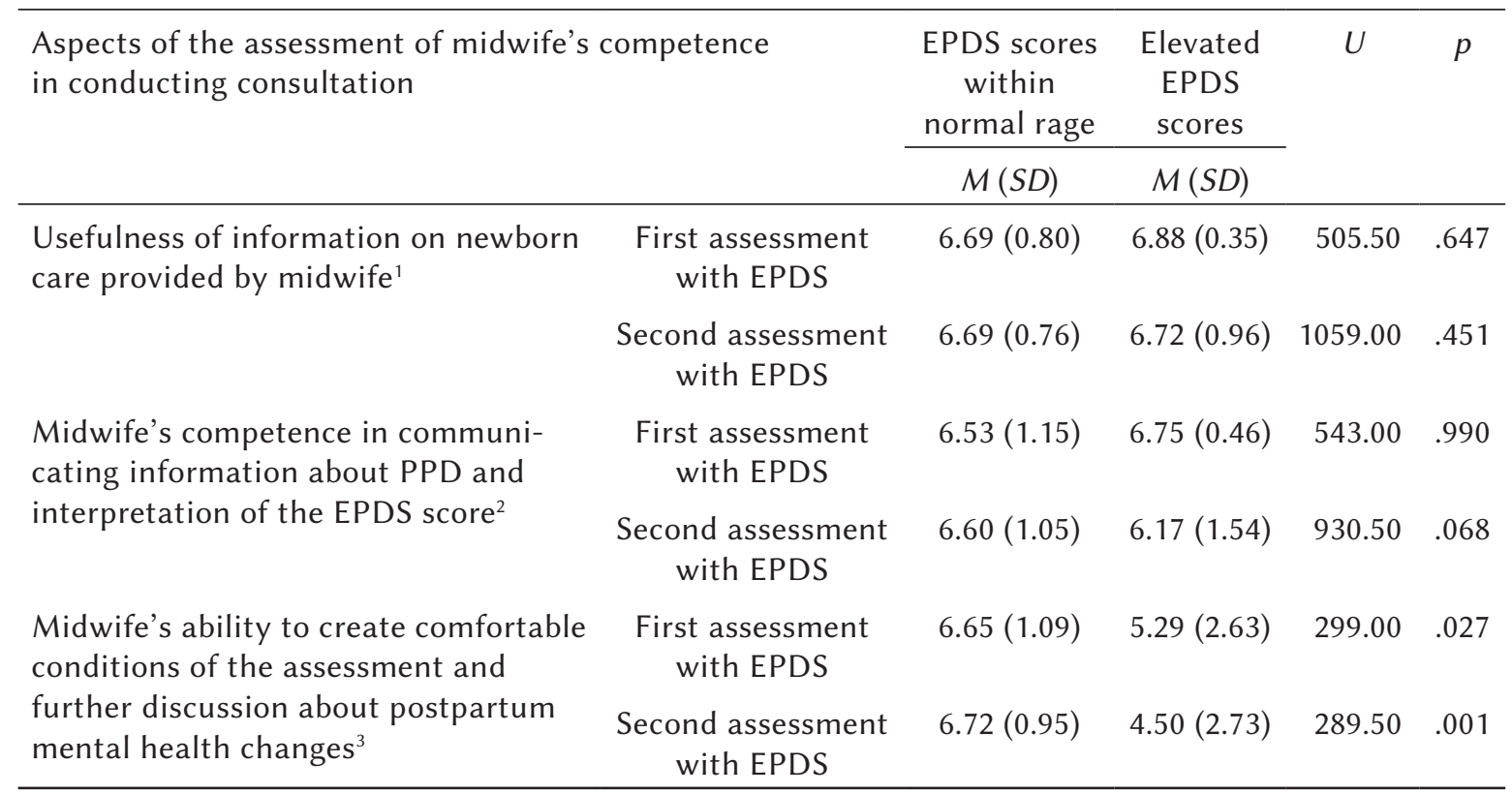

Note. ${ }^{1}$ 7-point Likert scale from 1 (useless) to 7 (very useful); ${ }^{2}$ 7-point Likert scale from 1 (low) to 7 (high); ${ }^{3}$ 7-point Likert scale from 1 (a feeling of awkwardness) to 7 (a feeling of very good comfort).

\section{Table 4}

Differences in evaluations of midwives' competencies between women giving birth naturally $(n=90)$ and after C-section $(n=39)$ in the project 'Next Stop: MUM'

\begin{tabular}{|c|c|c|c|c|}
\hline \multirow[t]{2}{*}{$\begin{array}{l}\text { Aspects of the assessment of midwife's competence } \\
\text { in conducting consultation }\end{array}$} & $\begin{array}{l}\text { Women giving } \\
\text { birth naturally }\end{array}$ & $\begin{array}{l}\text { Women after } \\
\text { C-section }\end{array}$ & \multirow[t]{2}{*}{$U$} & \multirow[t]{2}{*}{$p$} \\
\hline & $M(S D)$ & $M(S D)$ & & \\
\hline $\begin{array}{l}\text { Usefulness of information on newborn care provided } \\
\text { by midwife }{ }^{1}\end{array}$ & $6.80(0.68)$ & $6.54(0.91)$ & 1493.50 & .052 \\
\hline $\begin{array}{l}\text { Midwife's competence in communicating information } \\
\text { about PPD and interpretation of the EPDS score }\end{array}$ & $6.74(0.65)$ & $6.23(1.61)$ & 1527.50 & .095 \\
\hline $\begin{array}{l}\text { Midwife's ability to create comfortable conditions of } \\
\text { the assessment and further discussion about postpar- } \\
\text { tum mental health changes }\end{array}$ & $6.62(1.13)$ & $6.52(1.48)$ & 1349.50 & .718 \\
\hline
\end{tabular}

negative correlation between obtained EPDS scores and the assessment of midwives' competence in creating comfortable conditions of the assessments and further discussion about postpartum mental health changes. This was also supported by the results of the additional analysis in subgroups distinguished on the basis of cut-off points for clinical results obtained on the EPDS. Those women who were characterized by a higher (clinical) severity of depressive symptoms assessed midwives' competencies as lower in this regard. Furthermore, although women giving birth naturally as well as those having a caesarean section assessed midwives' competencies in conducting postpartum screening at a similar level, those who had a CS tend to give lower scores when considering the usefulness of information on newborn care provided by midwives. 
Probably women with elevated results on the EPDS are more critical in the assessment of midwives' competences, because their mental state (depressive symptoms) influences the perception of reality and received care. People with depressive symptoms are often more severe in their assessment of other people, perceive situations more negatively, and perceive various events as worse (Beck, 1964; Haaga \& Beck, 1995). Because their assessment is more severe, they can be perceived by others as people with high expectations, harsh and unfriendly (Feltham, 2016; Steger \& Kashdan, 2009). Additionally, Dinos et al. (2004) suggested that patients with depression often do not agree with describing their mental state using the term of depression. Thus, the observed criticism toward midwives' competencies may also be associated with a lack of internal agreement on the received information on the obtained score provided by the midwife.

Furthermore, women after CS seem to have greater needs/expectations regarding information on newborn care provided by midwives. This result is highly consistent with the cited literature. In HerishanuGilutz et al.'s study (2009), mothers after CS described alienation from the infant on encountering her/him; primal difficulties in holding; a 'mechanistic' pattern of childcare at home; over-apprehension and fear of a cradle death. Higher need for information on newborn care may be associated with the results concerning different brain responsiveness and neurohormonal regulation in a vaginal delivering mother and mothers after a C-section. Mothers after CS may need some additional information, assistance and confirmation that they are good enough mothers because of a probable difference in neurohormonal regulation introduced by this type of delivery (Swain et al., 2008). Moreover, due to the greater risk of postpartum complications and longer recovery period (Vikhareva Osser \& Valentin, 2010; Xu et al., 2017), women after CS need to focus more on the care of their own body (scar) often at a cost of insufficient time to get acquainted with information on newborn care (Beattie et al., 1994). Yet, on the other hand, babies who do not develop properly are more often born via CS (Patel et al., 2005) or such childbirth contributes to later medical complications (Christensson et al., 1993; Roth-Kleiner et al., 2003). Therefore, women may hope that during consultation with midwives they will be able to supplement the detailed knowledge about newborn care or that midwives will help them enter into a relationship with the baby (e.g. by performing 'a symbolic adoption' of their infants, described by Herishanu-Gilutz et al., 2009).

\section{IMPLICATIONS FOR PRACTICE AND/OR POLICY}

The results of this study are of great clinical importance: lower assessments of midwives' competencies going hand in hand with higher results obtained on the EPDS scale by women suggests that new mothers with PPD symptoms may be reluctant to use further assistance and seek appropriate treatment. This may result in the frustration of a midwife, who may be outraged by the patient's attitude towards consultation. In the absence of understanding for the patient's condition, midwives may not be willing to interact with a mother and offer her help and support (Jones et al., 2012a). Midwives should therefore be aware and prepared for the possible critical attitude of patients, which may be a sign of depression. During training, it is worth including a thematic block devoted to depressive symptoms, which should be supported by illustrations of cases of difficult interactions that midwives may come across during their work. The ability to create a friendly condition in spite of adversity can significantly contribute to the desire of women to undergo screening, discussion about the result and further treatment (Jones et al., 2012b; McIntosh, 1993; Nicole et al., 2007). It should be remembered, however, that midwives may require additional support to deal with difficult situations and their own feelings during such consultations. Supervision, which allows discussion of difficult situations arising at work and understanding one's own reactions and emotions, can significantly strengthen the competencies of midwives in conducting such consultations.

Moreover, midwives should be aware of the increased needs of women after CS in the field of gaining information on newborn care. One of our suggestions is to offer additional educational materials in the form of e.g. books for women who need more extensive knowledge or to prepare a list of reliable sources from which women could derive information, e.g. blogs, support groups, hospital's website. The increased need for information on newborn care among CS mothers may result from their greater difficulties in transition to parenthood and the need for external support in this process.

The perception of the screening procedure (in order to detect perinatal mental health problems) as a positive experience is important as it may alleviate clinicians' and policy-makers' concerns regarding the negative impact of mental health screening on postpartum women and perception of healthcare workers as those who interfere in a woman's private affairs. Pointing to the benefits of such a screening test the possibility of getting quick (and thus, with high probability, effective) help, thanks to which a mother can quickly return to mental balance and fully enjoy motherhood - can significantly affect women's willingness to undergo such a perinatal assessment. Creating comfort by establishing a relationship of trust, being aware of and eliminating stigmatizing behaviours (e.g. by informing about the universality of mood disorders in the postpartum period), and using basic relationship skills (e.g. eye contact; active listening) could be helpful in order to optimize the screen-
Mother's perception of screening for perinatal depression 
ing process and early detection of depressive symptoms. At the same time, it is worth remembering that a woman's mental state should be monitored in both periods: during pregnancy and after birth (Jomeen et al., 2009; Jones et al., 2012b), because her mental state can significantly affect the course of pregnancy and childbirth and moderate the quality of the relationship with the newborn in the postpartum period.

Furthermore, our project 'Next Stop: MUM' could serve as a basis for a recommendation to implement such a prevention programme in other regions of Poland as well as to offer all Polish nurses and midwives training in the area of screening for postpartum depression and offering women (with elevated severity of depressive symptoms) quick postpartum help from the National Health Fund. We believe that due to the imposed obligation to provide screening for postpartum depression, all midwives in Poland should have access to free training, which would include the identification of screening methods, interpretation of the results and possible referral pathways.

\section{LIMITATIONS}

The results of the research concern a selected group of women participating in the project, to whom the midwives applied the recommendations of the Polish Ministry of Health; thus special care should be taken in extrapolating conclusions from this study to the population as we do not have knowledge whether and how screening is provided in other regions where no such project has been implemented.

Moreover, the majority of the study group consisted of women from very large cities and with good or very good living standards. Thus, we recommend caution when extrapolating results of this study, as we do not know to what extent these demographic variables affected the results of our study, or whether women from other/less favourable socio-economic conditions would similarly evaluate the activities of midwives.

\section{FURTHER RESEARCH}

In further research, it is strongly recommended to assess whether (and in what percentage) women in Poland are screened for postpartum depression in accordance with the new national standard of perinatal care (Dziennik Ustaw, 2018). It is worthwhile in subsequent studies to assess how these tasks are carried out in other regions of Poland (not covered by the project 'Next Stop: MUM') - whether women are diagnosed with depression, what information is given to them, what kind of help is provided and how satisfied they are with the work of a midwife. Additionally, in our future studies we will try to expand the group of participants to those who live in less favourable socio- economic conditions as well as to those who live in rural areas where quick and direct access to medical care is often more limited than in cities.

Moreover, we are planning further research including both the attitudes and the needs of mothers and healthcare professionals regarding screening for postpartum depression. We would also like to evaluate the effectiveness of psychological training for midwives and paediatric nurses (concerning perinatal mental health problems but also communication skills). We are also planning to conduct qualitative studies regarding psychological consultations which are offered in our project.

\section{CONCLUSIONS}

The results of this study are important in the light of our previous research which revealed that at the beginning of 2019 Polish midwives perceived their preparation for the mental health screening and providing care for mothers with depressive symptoms at a relatively low level (Chrzan-Dętkoś \& WalczakKozłowska, 2020). The vast majority of midwives taking part in our previous study $(80 \%)$ admitted that they were not adequately educationally prepared for the screening and providing care for women with antenatal depression and/or PPD. However, on the basis of the results from this research, we can conclude that in general new mothers perceive midwives as persons competent in providing information on postpartum depression and EPDS scores, creating comfortable conditions for screening and discussing the postpartum mental health changes. Midwives' competencies are assessed as lower by those mothers who have intensified symptoms of postpartum depression.

\section{RefERENCES}

Andersson, L., Sundström-Poromaa, I., Wulff, M., Åström, M., \& Bixo, M. (2004). Implications of antenatal depression and anxiety for obstetric outcome. Obstetrics \& Gynecology, 104, 467-476. https:// doi.org/10.1097/01.AOG.0000135277.04565.e9

Bayrampour, H., McNeil, D. A., Benzies, K., Salmon, C., Gelb, K., \& Tough, S. (2017). A qualitative inquiry on pregnant women's preferences for mental health screening. BMC Pregnancy and Childbirth, 17, 339. https://doi.org/10.1186/s12884-017-1512-4

Beattie, P. G., Rings, T. R., Hunter, M. F., \& Lake, Y. (1994). Risk factors for wound infection following caesarean section. Australian and New Zealand Journal of Obstetrics and Gynaecology, 34, 398-402. https://doi.org/10.1111/j.1479-828X.1994.tb01256.x

Beck, A.T. (1964). Thinking and depression: II. Theory and therapy. Archives of General Psychiatry, 10, 561-571. https://doi.org/10.1001/archpsyc. 1964.01720240015003 
Christensson, K., Siles, C., Cabrera, T., Belaustequi, A., de la Fuente, P., Lagercrantz, H., Puyol, P., \& Winberg, J. (1993). Lower body temperatures in infants delivered by caesarean section than in vaginally delivered infants. Acta Paediatrica, 82, 128-131. https://doi.org/10.1111/j.1651-2227.1993.tb12622.x

Chrzan-Dętkoś, M., \& Walczak-Kozłowska, T. (2020). Antenatal and postnatal depression - Are Polish midwives really ready for them? Midwifery, 83, 102646. https://doi.org/10.1016/j.midw.2020.102646

Cornford, C. S., Hill, A., \& Reilly, J. (2007). How patients with depressive symptoms view their condition: a qualitative study. Family Practice, 24, 358-364. https://doi.org/10.1093/fampra/cmm032

Cox, J. L., Holden, J. M., \& Sagovsky, R. (1987). Detection of postnatal depression. Development of the 10-item Edinburgh Postnatal Depression Scale. British Journal of Psychiatry, 150, 782-786. https:// doi.org/10.1192/bjp.150.6.782

Dayan, J., Creveuil, C., Marks, M. N., Conroy, S., Herlicoviez, M., Dreyfus, M., \& Tordjman, S. (2006). Prenatal depression, prenatal anxiety, and spontaneous preterm birth: a prospective cohort study among women with early and regular care. Psychosomatic Medicine, 68, 938-946. https://doi. org/10.1097/01.psy.0000244025.20549.bd

Dinos, S., Stevens, S., Serfaty, M., Weich, S., \& King, M. (2004). Stigma: The feelings and experiences of 46 people with mental illness. Qualitative study. The British Journal of Psychiatry, 184, 176-181. https:// doi.org/10.1192/bjp.184.2.176

Dziennik Ustaw (2018, poz. 1756). Rozporzadzenie Ministra Zdrowia z dnia 16 sierpnia 2018 r. w sprawie standardu organizacyjnego opieki okotoporodowej [Journal of Laws of the Republic of Poland (2018 item 1756). Regulation of the Minister of Health of August 16, 2018 on the organizational standard of perinatal care].

Earls, M. F., Yogman, M. W., Mattson, G., Rafferty, J., \& Committee on Psychosocial Aspects of Child and Family Health (2019). Incorporating recognition and management of perinatal depression into pediatric practice. Pediatrics, 143, e20183259. https://doi.org/10.1542/peds.2018-3259

Felder, J. N. (2019). Implementing the USPSTF recommendations on prevention of perinatal depression - opportunities and challenges. JAMA Internal Medicine, 179, 467-468. https://doi.org/10.1001/ jamainternmed.2018.7729

Feltham, C. (2016). Depressive realism: Interdisciplinary perspectives. Taylor \& Francis.

Fonseca, A., Gorayeb, R., \& Canavarro, M. C. (2015). Women's help-seeking behaviours for depressive symptoms during the perinatal period: Sociodemographic and clinical correlates and perceived barriers to seeking professional help. Midwifery, 31, 1177-1185. https://doi.org/10.1016/j. midw.2015.09.002
Goldenberg, R. L., Culhane, J. F., lams, J. D., \& Romero, R. (2008). Epidemiology and causes of preterm birth. The Lancet, 371, 75-84. https://doi. org/10.1016/S0140-6736(08)60074-4

Grote, N. K., Bridge, J. A., Gavin, A. R., Melville, J. L., lyengar, S., \& Katon, W. J. (2010). A meta-analysis of depression during pregnancy and the risk of preterm birth, low birth weight, and intrauterine growth restriction. Archives of General Psychiatry, 67, 1012-1024. https://doi.org/10.1001/archgenpsychiatry.2010.111

Haaga, D. A., \& Beck, A. T. (1995). Perspectives on depressive realism: Implications for cognitive theory of depression. Behaviour Research and Therapy, 33, 41-48. https://doi.org/10.1016/0005-7967(94)E0016-C

Herishanu-Gilutz, S., Shahar, G., Schattner, E., Kofman, O., \& Holcberg, G. (2009). On becoming a first-time mother after an emergency caesarean section: a journey from alienation to symbolic adoption. Journal of Health Psychology, 14, 967-981. https://doi.org/10.1177/1359105309341205

Jomeen, J., Glover, L. F., \& Davies, S. A. (2009). Midwives' illness perceptions of antenatal depression. British Journal of Midwifery, 17, 296-303. https:// doi.org/10.12968/bjom.2009.17.5.42221

Jones, C. J., Creedy, D. K., \& Gamble, J. A. (2011). Australian midwives' knowledge of antenatal and postpartum depression: a national survey. Journal of Midwifery \& Women's Health, 56, 353-361. https://doi.org/10.1111/j.1542-2011.2011.00039.x

Jones, C. J., Creedy, D. K., \& Gamble, J. A. (2012a). Australian midwives' awareness and management of antenatal and postpartum depression. Women and Birth, 25, 23-28. https://doi.org/10.1016/j.wombi.2011.03.001

Jones, C. J., Creedy, D. K., \& Gamble, J. A. (2012b). Australian midwives' attitudes towards care for women with emotional distress. Midwifery, 28, 216-221. https://doi.org/10.1016/j.midw.2010.12.008

Kendig, S., Keats, J. P., Hoffman, M. C., Kay, L. B., Miller, E. S., Moore Simas, T. A., Frieder, A., Hackley, B., Indman, P., Raines, C., Semenuk, K., Wisner, K. L., \& Lemieux, L. A. (2017). Consensus bundle on maternal mental health: Perinatal depression and anxiety. Journal of Obstetric, Gynecologic \& Neonatal Nursing, 46, 272-281. https://doi.org/10.1016/j. jogn.2017.01.001

Kingston, D. E., Austin, M. P., McDonald, S. W., Vermeyden, L., Heaman, M., Hegadoren, K., Lasiuk, G., Kingston, J., Sword, W., Jarema, K., Veldhuyzen van Zanten, S., McDonald, S. D., \& Biringer, A. (2015a). Pregnant women's perceptions of harms and benefits of mental health screening. PLoS One, 10, e0145189. https://doi.org/10.1371/journal.pone.0145189

Kingston, D. E., Biringer, A., McDonald, S. W., Heaman, M. I., Lasiuk, G. C., Hegadoren, K. M., McDonald, S. D., Veldhuyzen van Zanten, S., Sword, W., Kingston, J. J., Jarema, K. M., Vermeyden, L., \& Aus-
Mother's perception of screening for perinatal depression 
tin, M. P. (2015b). Preferences for mental health screening among pregnant women: a cross-sectional study. American Journal of Preventive Medicine, 49, e35-e43. https://doi.org/10.1016/j.amepre.2015.03.026

Kingston, D. E., Biringer, A., Toosi, A., Heaman, M. I., Lasiuk, G. C., McDonald, S. W., Kingston, J., Sword, W., Jarema, K., \& Austin, M. P. (2015c). Disclosure during prenatal mental health screening. Journal of Affective Disorders, 186, 90-94. https:// doi.org/10.1016/j.jad.2015.07.003

Magdalena

Chrzan-Dętkoś,

Tamara Z.

Walczak-

Kozłowska

Knight, M., Nair, M., Tuffnell, D., Shakespeare, J., Kenyon, S., \& Kurinczuk, J. J. (2017). Saving lives, improving mothers' care - lessons learned to inform maternity care from the UK and Ireland confidential enquiries into maternal deaths and morbidity 2014-2016. National Perinatal Epidemiology Unit, University of Oxford.

Kozhimannil, K. B., Pereira, M. A., \& Harlow, B. L. (2009). Association between diabetes and perinatal depression among low-income mothers. JAMA, 301, 842-847. https://doi.org/10.1001/jama.2009.201

Kurki, T., Hiilesmaa, V., Raitasalo, R., Mattila, H., \& Ylikorkala, O. (2000). Depression and anxiety in early pregnancy and risk for preeclampsia. Obstetrics \& Gynecology, 95, 487-490. https://doi.org/10.1016/ S0029-7844(99)00602-X

Logsdon, M. C., Tomasulo, R., Eckert, D., Beck, C., \& Dennis, C. L. (2012). Identification of mothers at risk for postpartum depression by hospital-based perinatal nurses. MCN: The American Journal of Maternal/Child Nursing, 37, 218-225. https://doi. org/10.1097/NMC.0b013e318251078b

McIntosh, J. (1993). Postpartum depression: Women's help-seeking behaviour and perceptions of cause. Journal of Advanced Nursing, 18, 178-184. https:// doi.org/10.1046/j.1365-2648.1993.18020178.x

Mollart, L., Newing, C., \& Foureur, M. (2009). Midwives' emotional wellbeing: Impact of conducting a structured antenatal psychosocial assessment (SAPSA). Women and Birth, 22, 82-88. https://doi. org/10.1016/j.wombi.2009.02.001

Netsi, E., Pearson, R. M., Murray, L., Cooper, P., Craske, M. G., \& Stein, A. (2018). Association of persistent and severe postnatal depression with child outcomes. JAMA Psychiatry, 75, 247-253. https:// doi.org/10.1001/jamapsychiatry.2017.4363

Nicole, L., Duffett-Leger, L., Stewart, M., Hegadoren, K., Dennis, C. L., Rinaldi, C. M., \& Stoppard, J. (2007). Canadian mothers' perceived support needs during postpartum depression. Journal of Obstetric, Gynecologic \& Neonatal Nursing, 36, 441-449. https:// doi.org/10.1111/j.1552-6909.2007.00174.x

O'Hara, M. W., \& McCabe, J. E. (2013). Postpartum depression: Current status and future directions. Annual Review of Clinical Psychology, 9, 379-407. https:// doi.org/10.1146/annurev-clinpsy-050212-185612

Orr, S. T., \& Miller, C. A. (1995). Maternal depressive symptoms and the risk of poor pregnancy outcome:
Review of the literature and preliminary findings. Epidemiologic Reviews, 17, 165-171. https://doi. org/10.1093/oxfordjournals.epirev.a036172

Patel, R. R., Peters, T. J., \& Murphy, D. J. (2005). Prenatal risk factors for caesarean section. Analyses of the ALSPAC cohort of 12944 women in England. International Journal of Epidemiology, 34, 353-367. https://doi.org/10.1093/ije/dyh401

Polityka Zdrowotna (2019). Polska z jednym z najwyższych odsetków cięć cesarskich w Europie [Poland with one of the highest caesarean section rates in Europe]. Retrieved from https://www.politykazdrowotna.com/41449, polska-z-jednym-znajwyzszych-odsetkow-ciec-cesarskich-w-europie [accessed July 21, 2020]

Roth-Kleiner, M., Wagner, B. P., Bachmann, D., \& Pfenninger, J. (2003). Respiratory distress syndrome in near-term babies after caesarean section. Swiss Medical Weekly, 133, 283-288.

Rubertsson, C., Wickberg, B., Gustavsson, P., \& Rådestad, I. (2005). Depressive symptoms in early pregnancy, two months and one year postpartum-prevalence and psychosocial risk factors in a national Swedish sample. Archives of Women's Mental Health, 8, 97-104. https://doi.org/10.1007/s00737-005-0078-8

Steger, M. F., \& Kashdan, T. B. (2009). Depression and everyday social activity, belonging, and well-being. Journal of Counseling Psychology, 56, 289-300. https://doi.org/10.1037/a0015416

Swain, J. E., Tasgin, E., Mayes, L. C., Feldman, R., Todd Constable, R., \& Leckman, J. F. (2008). Maternal brain response to own baby-cry is affected by caesarean section delivery. Journal of Child Psychology and Psychiatry, 49, 1042-1052. https:// doi.org/10.1111/j.1469-7610.2008.01963.x

Vikhareva Osser, O., \& Valentin, L. (2010). Risk factors for incomplete healing of the uterine incision after caesarean section. BJOG: An International Journal of Obstetrics \& Gynaecology, 117, 1119-1126. https://doi.org/10.1111/j.1471-0528.2010.02631.x

Wallis, A. B., \& Saftlas, A. F. (2009). Is there a relationship between prenatal depression and preeclampsia? American Journal of Hypertension, 22, 345-346. https://doi.org/10.1038/ajh.2009.28

Wisner, K. L., Miller, E. S., \& Tandon, D. (2019). Attention to prevention. Can we stop perinatal depression before it starts? JAMA Psychiatry, 76, 355-356. https://doi.org/10.1001/jamapsychiatry.2018.4085

Wu, J., Viguera, A., Riley, L., Cohen, L., \& Ecker, J. (2002). Mood disturbance in pregnancy and the mode of delivery. American Journal of Obstetrics and Gynecology, 187, 864-867. https://doi.org/10.1067/ mob.2002.127126

Xu, H., Ding, Y., Ma, Y., Xin, X., \& Zhang, D. (2017). Caesarean section and risk of postpartum depression: a meta-analysis. Journal of Psychosomatic Research, 97, 118-126. https://doi.org/10.1016/j.jpsychores.2017.04.016 